\title{
Beauty Economy: A Practical Approach to Effectively Link Poverty Alleviation with Rural Vitalization
}

\author{
Mengsheng Cai ${ }^{1, a}$
}

\author{
${ }^{1}$ JiangSu Police Institute, Nanjing, JiangSu, China \\ a250075937@qq.com
}

\begin{abstract}
The goal of "beauty economy" construction lies in the comprehensive realization of "natural beauty, infrastructure beauty, villagers beauty, cultural beauty" in rural areas. In the process of effectively linking poverty alleviation with rural revitalization, the development model of "beauty economy" provides a more efficient path for rural revitalization. Taking the beneficial exploration of "beauty economy" in JiangSu Province as a case study, the study shows the actual progress of village cleaning action to improve rural living environment, ecological agriculture to promote more sustainable agricultural development mode, and beauty economy to improve farmers' life quality. This paper analyzes the challenges of the construction of "beauty economy", such as the depth of villagers' participation in "beauty economy", the hollowing out of village population and the homogenization of development mode. The practical paths of "beauty economy" such as enhancing villagers' ability to participate in "beauty economy", integrating rural resources to build infrastructure, and creating unique rural brands are put forward.
\end{abstract}

Keywords: Beauty economy, poverty alleviation, rural revitalization

\section{INTRODUCTION}

Climate change affects the physical health, food supply, housing security and job security of each and every one of us. So far, the earth is $1.1^{\circ} \mathrm{C}$ warmer than it was at the end of the 19th century; the past decade (2011-2020) was the warmest on record [1]. Inger Andersen, executive director of UNEP, said: "We need a step-change in the financing and implementation of adaptation to significantly reduce the harm and damage we suffer from climate change." Beauty economy is the industrialization, capitalization and financialization of natural resources, and a new economic model to achieve green and sustainable development ${ }^{[2]}$. Economic and social development should be integrated with the response to climate change, and in the process of effectively linking poverty alleviation with rural revitalization, we need to vigorously develop a beauty economy. The development of beauty economy is not only conducive to the realization of people's yearning for a better life, but also conducive to the protection of our natural environment, and then achieve economic development and environmental protection benign operation and sustainable development. Taking the development of beauty economy in JiangSu Province as a case study, this study presents the practice of promoting rural revitalization by transforming beautiful ecology into beauty economy, and studies the idea that clear water and green mountains are gold and silver mountains. This study analyzes the challenges faced by sustainable development in the effective connection between poverty alleviation and rural revitalization, and proposes coping strategies for beautiful economic development, so as to provide reference for human beings to better cope with climate change and human sustainable development.

\section{EXPLICIT BEHAVIOR: THE MAIN PRACTICE OF JIANGSU BEAUTY ECONOMY}

JiangSu province has put forward the macro blueprint strategy of "strong economy, rich people, beautiful environment and high social civilization". With the implementation of a series of measures such as rural revitalization and improvement of rural living environment, the rural ecological environment in JiangSu Province has become more beautiful, the agricultural development mode has become more green and environmentally friendly, and the happiness index of farmers has become higher ${ }^{[3]}$. 


\subsection{Village cleaning activities to improve the rural living environment}

The small toilet connects the big dream. In order to lay a good foundation for the beauty economy, JiangSu province focuses on promoting the rural toilet revolution. In JiangSu province, rural toilet renovation has been included in provincial government livelihood projects for many years. Harmless household sanitary toilets are basically popularized in rural areas of the whole province. The collection, transportation and treatment system of rural household garbage has been fully implemented in the province. The centralized collection and transportation rate of rural household garbage in the province exceeded $99 \%$, and hundreds of town and townships carried out a pilot work of sorting rural household garbage. Sewage treatment facilities have been built in $74.6 \%$ of villages.

\subsection{Ecological agriculture promotes more sustainable agricultural development mode}

Agriculture is to add green industry, the countryside is green pronoun. JiangSu province adheres to the concept of "clear water and green mountains are gold and silver mountains" and promotes the sustainable development strategy of "stable output and guaranteed supply" of important agricultural products. Through the cultivation and expansion of high-quality rice, wheat, green vegetables, ecological livestock and poultry, characteristic aquatic products and other advantageous industries, JiangSu province not only effectively guaranteed the "rice bag" and "vegetable basket" of the residents, but also effectively brought into play the "ecological" function of farmland ecosystem and paddy field constructed wetland. Their will gradually establish a recycling, disposal and utilization system for crop straw, livestock and poultry manure, waste agricultural film and pesticide packaging waste.

\subsection{Beauty economy improves the living quality of farmers}

A clean, tidy and orderly rural environment is a new growth point for improving farmers' quality of life. JiangSu province has improved the quality of life of farmers by building beautiful homes with both traditional and modern agricultural flavor. First, a beautiful living environment drives the high-quality development of new industries and forms of business, and makes a leap from "beautiful ecology" to "beauty economy". Second, beautiful living environment promotes the construction of high standards of local culture and civilization. To sum up and popularize the "Experience of Mazhuang", further implement the project to improve the local customs and civilization, and fully show the new look and vigor of contemporary farmers. Third, the beautiful living environment promotes efficient rural governance. Publicity and education of rural ecological civilization and improvement of rural living environment will be incorporated into village regulations and covenants, and excellent farming culture will be incorporated into rural governance. Farmers have taken the initiative to participate in building a beautiful homeland, enhancing their sense of gain, happiness and security through joint construction and sharing.

\section{POTENTIAL RISKS: CHALLENGES IN BUILDING A "BEAUTY ECONOMY"}

\subsection{The depth of villagers' participation in "beauty economy" needs to be strengthened}

In rural areas, some villagers have been working outside their hometown for a long time. They do not pay enough attention to what happens in their hometown and do not participate in the process of rural revitalization. As a result, individual villagers do not pay attention to environmental protection, and the behavior of littering and piling in the village often occurs. Even from the current environment of China, rural economic development is still not optimistic enough, which makes them only care about immediate interests and lack long-term vision when seizing the opportunity of beautiful rural construction and beauty economy ${ }^{[4]}$. In particular, some older villagers (over 65 years old) are not well educated and lack awareness of environmental protection.

\subsection{Population hollowing leads to insufficient infrastructure construction in some rural areas}

Improving rural infrastructure is an important support for developing a "beauty economy". As a large number of rural people move into cities, economic input and daily maintenance of rural infrastructure will be impacted. Weak rural infrastructure has begun to emerge, mainly reflected in poor drinking water quality, aging power lines, old transformers, low voltage, damaged roads and so on. This is very unfavorable to the sustainable development of rural economy, especially to the sustainable promotion of "beauty economy". Rural infrastructure is the basic safeguard beautiful rural construction, the lack of supporting facilities will limit the development of the "beauty economy", although some country has the rich cultural resources and economic value, but because of a lack of parking lot, bathrooms, recycling facilities, led billboard, leisure square, children's play area is equipped with facilities, directly restricted the economic development of rural tourism. 


\subsection{The homogenization of development mode affects the healthy development of "beauty economy"}

\begin{abstract}
"Beauty economy" has been recognized by more and more people, but with it comes the homogenization of development model. First, rural development standards are divorced from rural realities. Some villagers simply think that "beautiful village" is to imitate the architectural style of the city, building archway, artificial lake, sculpture, rockery, commercial street and other buildings at will. However, this construction mode destroys the original natural scenery of the countryside. Second, the development of rural construction mode "context" is insufficient. In the construction of "beautiful country", and some villages in the study of "cultural model" success, without thinking of the endless characterizes some historical figures, the construction of antique buildings, add some and rural theme style not harmonious landscape elements, not only did not learn the connotation of "culture", also lost its own characteristics.
\end{abstract}

\section{FEASIBLE APPROACH: AN EFFECTIVE DEVELOPMENT PATH OF "BEAUTY ECONOMY"}

\subsection{Enhance villagers' ability to participate in "beauty economy"}

Issues concerning rural agriculture and farmers are fundamental to the national economy and people's livelihood. Strong measures should be taken to encourage villagers to participate in the building of a "beauty economy". First, it should play a positive role in improving the overall quality of farmers and enhancing their livelihood ability [5]. Second, in order to make farmers share the benefits of beautiful countryside construction fairly, it is necessary to further enhance the participation level of farmers and attract them to participate in rural construction. ${ }^{[6]}$. Third, organize farmers economically, safeguard their rights and interests, increase their enthusiasm and initiative in building beautiful villages, and consolidate the foundation for endogenous development in rural areas.

\subsection{Integrate rural resources to build infrastructure}

Simply relying on mountains and rivers is not reliable, operating landscape is the right choice ${ }^{[7]}$. First, we need to comprehensively narrow the gap between urban and rural areas and work hard to improve infrastructure and public services in rural areas. The construction of rural infrastructure and new forms of business can alleviate the vulnerability of traditional agricultural land management income. Second, the renovation work to beautify the environment as the goal, to dismantle illegal buildings as the focus, to increase infrastructure construction efforts. Eliminating environmental pollution existing in roads and river courses. Third, highlight the needs of industrial development. The main reason for the decline and blight of some villages is that there is no rural industry to support them ${ }^{[8]}$. Only with industries can we retain talents, especially young people.

\subsection{Build a unique rural brand}

A region is a place for human activities engaged in production and life, and a complete geographical space with certain self-discipline and individuality in economic, social and natural aspects ${ }^{[9]}$. First, strengthen personnel training. Focus on village cadres, rich leaders, individual business and professional skills training. Adopt a combination of inviting in and going out to improve the training effect. Second, rural branding should be regarded as an effective starting point for the construction of beautiful villages in the new era and widely publicized through various ways. Third, we should adapt measures to local conditions and village conditions, combine the different characteristics of each village, and form a development pattern of "one village, one product". At the same time, deeply excavate cultural resources and refine historical and cultural values. The most valuable resources of rural brand are ecological environment and folk culture.

\section{CONCLUSION}

The era that rural areas can survive only on agriculture has come to an end, and it is necessary to build a long-term mechanism after building a beautiful countryside. In the process of effectively linking poverty alleviation with rural vitalization, we should not only review the advanced experience we have gained, but also recognize the shortcomings and potential risks. It is a major task to promote the long-term development of rural areas and contribute to China's economic and social transformation and upgrading. In the future, we should set up the correct development concept of "beauty economy", plan and build beautiful countryside with the concept of beauty economy, and explore more practical paths for the realization of overall urban-rural construction and rural revitalization.

\section{FOUNDATION PROJECT}

This research was supported by the "Qinglan Project" for Jiangsu Province. A Part of the "Study on the practice path of Jiangsu Province's beautiful economy from the perspective of rural revitalization"

(2019SJA0455) of Jiangsu Provincial Department of Education. 


\section{REFERENCES}

[1] UN.(2021)Greenhouse gas concentrations are at their highest levels in two million years. https://www.un.org/zh/climatechange/what-is-clim ate-change.

[2] Zhang,B.X., Li C.L.(2019) Management ecology: the logic of beautiful economic development. Governance Studies,2:50-58.

[3] shao,Q.Q. (2021)"Beautiful Ecology" becomes "Beautiful Economy". http://www.xdkb.net/p1/js/20210513/177835.html.

[4] Huang, H., Xiao Y.L., (2021) Beautiful countryside, characteristic town and rural revitalization fit the interactive relationship research, The southern rural,3:34- 39+45.

[5] Wu, Y.L. (2021) Research on the construction of new "beautiful village" in the poverty-stricken area under the background of tourism poverty alleviation, The agricultural economy,1:15-22.

[6] Wang, W.L. (2016) Reflections on the Construction of Beautiful Countryside in China and suggestions on policy adjustment, Problems of agricultural economy, 10:83-92.

[7] Zhang, H., Zhang M.S., (2020) Explore the practice mode of building follow-up management villages in Beautiful Countryside, Zhejiang Agricultural Sciences, 8: 1491-1495.

[8] Cheng, W.S. (2018) Rural revitalization will focus on industrial prosperity, Zhejiang Daily , 2018-10-10 (5).

[9] Zu, T.X. (2003) Discussion of agronomic roots, Renmin University of China Press, Bei Jing. 